\title{
Role-Taking, Emotion and the Two SELVES
}

\author{
Thomas SchefF
}

Abstract. This note links three hitherto separate subjects: role-taking, meditation, and theories of emotion, in order to conceptualize the makeup of the self. The idea of role-taking plays a central part in sociological theories of the self. Meditation implies the same process in terms of a deep self able to witness itself. Drama theories also depend upon a deep self that establishes a safe zone for resolving intense emotions. All three approaches imply both a creative deep self and the everyday self (ego) that is largely automated. The creativity of the deep self is illustrated with a real life example: an extraordinary psychotherapy experiment appears to have succeeded because it was based entirely on the intuitions of the therapist. At the other end from intuition, in one of her novels, Virginia Woolf suggested three crucial points about automated thought: incredible speed, role-taking, and by implication, the presence of a deep self. This essay goes on to explain how the ego is repetitive to the extent that it becomes mostly, and in unusual cases, completely automated (as in most dreams and all hallucinations). The rapidity of ordinary discourse and thought usually means that it is superficial, leading to greater and greater dysfunction, and less and less emotion. This idea suggests a new approach to the basis of 'mental illness' and of modern alienation.

Keywords: role-taking, ego, automation, deep self, meditation, emotion, intuition

Résumé. Dans cet article je me propose de lier trois sujets que l'on a l'habitude de traiter séparément: l'adoption d'un rôle, la méditation, et les théories des émotions. Ce faisant je souhaiterai mieux conceptualiser la constitution du moi. L'idée de prendre un rôle est au cœur des théories sociologiques du moi. La méditation suit le même processus dans le sens qu'un moi profond se voit capable de témoigner de ses propres opérations. Il est vrai aussi que les théories du drame dépendent de l'existence d'un moi profond qui établit une zone de sécurité où les émotions intenses peuvent se résoudre. Toutes les trois approches impliquent à la fois l'existence d'un moi profond créateur et d'un ego quotidien qui est, la plupart du temps, automatisé. On peut illustrer la créativité du moi profond par le biais d'un fait divers: le moi profond d'un thérapeute aurait produit une expérience efficace dans le domaine de la psychothérapie. Dans un de 
ses romans Virginia Woolf suggère trois points importants concernant la pensée automatique: une vitesse incroyable, l'adoption d'un rôle, et, par implication, la présence d'un moi profond. Mon étude cherche à expliquer comment l'ego se répète au sens qu'il devient principalement automatisé dans la majorité des cas, ou complètement automatisé dans quelques instances peu communes (comme dans la plupart des rêves et dans toutes les hallucinations). La rapidité du discours et de la pensée ordinaires signifie le plus souvent qu'elle est superficielle, et qu'elle mène à un dysfonctionnement grandissant et au moins en moins d'émotion. Ce concept ouvre la voie à une nouvelle perspective sur la «maladie mentale» et l'aliénation moderne.

Mots-clés: prise de rôle, ego, automatisation, moi profond, méditation, émotion, intuition

M ost of social psychology that is pursued in modern sociology, symbolic interaction, is based on the work of George H. Mead, a social philosopher. Central to his work is the idea of role-taking, which means that human societies are based on the individual's ability to imagine the point of view of other persons (1934). This process leads to an understanding that is accurate enough to create and maintain societies.

Although Mead did not refer to Cooley's (1922) contributions to the idea of role-taking, Cooley's work extends Mead's contributions. First, he made an addition that Mead didn't mention: "We live in the minds of others without knowing it." (1922, 208). This sentence describes the basis for all social relationships, a theory of mind, and also indicates that we are usually completely unaware of our own role-taking.

Intersubjectivity is built into human nature, yet modern societies make it almost invisible. Small children learn to go back and forth between their own point of view and imagining that of the other(s). At an early age, they seem to have become so adept and lightning quick that they forget they are doing it. In Cooley's words, it is like "the ground that bears us up when we walk," - taken for granted. The intersubjective bond to others becomes virtually invisible. Human communication is built upon intersubjective guessing because actual speech is complex, fragmented, contextualized, and therefore, if taken literally, usually unintelligible. To try to understand, the listener must move back and forth between own point of view and the imagined point of view of the speaker. Occasionally role-taking will be referred to in ordinary conversation, but only casually and in passing. For example, one might say to a friend, "We both know that (such and such...)." Even here, in the very act of imaginative mind reading, we usually not conscious that we are doing it.

Secondly, Cooley suggested that the dual quality of the self produces emotions. "[The self] seems to have three principal elements: 1 . The imagination of our appearance to the other person; 2. The imagination 
of his [or her] judgment of that appearance; 3 . Some sort of self feeling, such as pride or [shame]." $(1922,184)$ This passage proposes a looking glass self, the way in which social relationships give rise to a self, which in turn leads to pride or shame. Cooley's approach implies that almost all social interaction produces either pride or shame, and that these emotions are social as well as psychological. They signal the state of the relationship: either connectedness (pride) or disconnect (shame). He further implies that the degree of solidarity or alienation (connect/ disconnect) determines the prevailing emotional states in a society.

Neither Cooley nor Mead dealt with one implication of their idea of role-taking: that all humans have the capacity of looking at themselves, of being self-witnessing in a way that gives rise to huge leaps of insight. The novelist D. H. Lawrence, like many others, envisioned a hidden part of the self far beyond everyday life.

"There are vast realms of consciousness still undreamed of, vast ranges of experience, like the humming of unseen harps, we know nothing of, within us..." (1932).

His vision, and similar ones by others, propose that there is deep self hidden behind the everyday self, the ego. In our current world, this idea has been taken up under the label of 'spirituality'. Humans are thought to possess a spiritual side that can be accessed by religion or practices such as meditation. This idea creates two opposing camps - those who strongly believe in the deep self, and those who just as strongly reject it. The opposition usually invokes science: where is the proof? The believers see the question as irrelevant - there are intuitions that even though they have not, or cannot, be proven, are still immensely valuable and important.

This paper seeks to link the two seemingly incommensurate realms, following the advice of the early scientist and theologian Blaise Pascal (1660). Pascal thought that advances in understanding require both "the spirit of geometrie" (system) and "the spirit of finesse" (intuition). Intuition creates new ideas, system is needed to test their validity and refine them if they are valid. There is sizable literature on the deep self that offers examples like those below. So far, however, I have been unable to find literature that explains why the everyday self, the ego, is vastly outclassed by the deep self. My hypothesis is that the construction of the ego in modern societies aims at speed of response, giving rise to an ego that is largely repetitive and automatic, and therefore simplistic. 


\section{Creative Responses: The Deep Self}

There is also literature on the advantages of what is called 'mindfulness' (see Brown et al. 2007), and many studies and examples of how the best responses are often instantaneous, as in Gladwell's (2005) summary. However, this literature lacks the intensity of literary descriptions of the deep self, such as Lawrence. In particular, it doesn't have much to say about the extraordinary creativity of the deep self. One exception is the transcriptions of Gurdjieff's ideas by Ouspensky (1949). As the title of one his books (In Search for the Miraculous) suggests, Gurdjieff believed that the deep self created miracles. His ideas about the everyday self are discussed below, in connection with what will be called automaticity. More recent discussions are by Bargh and Chartrand (1999) and Moors and De Houwer (2006).

To provide an example of what seemed to me at the time a miracle, I recall an unbelievably successful experiment in psychotherapy. A group of Santa Barbara therapists was formed in 1970 by Marilyn Nadler, a licensed social worker and experienced therapist. The group was entirely her idea and she picked three other therapists to help her realize it. In hindsight, I believe that the reason she chose the three of us was that though we all had counselor's licenses, we had little training and experience. For this reason, perhaps, she thought she would be able to guide us with little friction, which proved to be the case.

The group provided forty-hour Intensives, a five day marathon for the clients that included twenty hours of individual psychotherapy (two 2 and $1 / 2$ hour sessions from each of the four of us) and twenty hours of attendance in self-help psychotherapy groups (Re-evaluation Counseling classes.) At the time there were many such groups available in Santa Barbara. These groups focused on the discharge of emotions, such as laughing and crying. Marilyn had met all three of us in Re-evaluation Counseling (RC) classes and workshops. However, her therapeutic method was not guided by RC practices, as will become clear below.

Marilyn had conceived the idea for the group because she was often called by other therapists (most of them in Los Angeles) for consultation about difficult or stalled cases. She set up an intensive procedure which we used with some sixty clients referred to her over a two-year period. We charged only $\$ 20$ an hour for the individual therapy, because it was an experiment. Since there was no charge for attendance at the RC classes, the total for the week was only $\$ 400$, which was seen as inexpensive even at that time.

The first two steps occurred before the Intensive began. Marilyn had a lengthy phone talk with the referring therapist. The four of us then had 
a short meeting in which she outlined what she had learned, and a bare beginning of a treatment plan (always brief). We met again on Wednesday at the halfway mark, to discuss what had happened in the first half of the Intensive, and how we might proceed in the last half.

This procedure was incredibly successful, according to the responses by the referring therapists. In the follow-up calls Marilyn made, about ten days after the end of therapy, ALL of the therapists expressed gratitude for the help provided to their clients, and also, frequently, asked questions about the methods that were used. As suggested below, they didn't get much of an answer to their questions about method. Apparently that didn't perplex them, because they still referred other clients. It should be noted that a $100 \%$ success rate is completely unknown in psychotherapy outcome studies.

The group ended in 1971, when Marilyn moved to Santa Cruz because her husband had taken a job there. The three of us who remained in Santa Barbara tried to carry on without her, but it was immediately obvious that we were no longer effective. I stopped offering therapy entirely, and let my license lapse. We had been superb therapists only because of Marilyn's subtle guidance.

My next step was to try to find out Marilyn's secret: how did she do it? It took many years questioning her, but I finally realized that she was unable to explain. As she told me, she just did what she had to do without thinking about it. It seems to me now that her success as a therapist can be explained in terms of the split between an everyday self and a deep self. Perhaps Marilyn had enough access to her deep self to intuitively recognize and solve (or come close enough to solving) one or more of the basic problems confronting each client, and to guide us amateur therapists into helping her do it.

\section{The Ego}

Most discussions of the deep self have little to say about the ordinary, everyday self. They clearly indicate that it functions at a low level, at least compared to the potential of the hidden self. Studies of awareness often report a low level of understanding other persons, for example, studies of false consensus and pluralistic ignorance on a large scale (Marks and Miller 1987; Miller et al. 2000) and on a small scale, shared obliviousness that exists inside families (Rosenblatt 2009).

However, Gurdjieff gave the nature of the everyday self some attention. He proposed that the ego mostly involved 'automation' - thoughts, feelings and actions outside of awareness $(1949,114)$. He went on to say 
that these components were not observed by what he called the observing self. But his explanation of automation does not go much further that.

Like Gurdjieff, most discussions of the deep self imply that the everyday self is almost always in charge, dominating the hidden self to the point that it is seldom available in consciousness. There is evidence for this implication in much of our behavior. For example, most people find the practice of meditation challenging. The goal is a seemingly simple one, to close one's eyes and to stay in the present, the here and now, by focusing one's attention on breathing, without thinking about other matters. Surprisingly, the beginner finds it is difficult to stay in the present for even a full minute because one's mind wanders off. The meditator quickly forgets the focus on breathing, thinking about work he or she has done or needs to be done, past or future conversations, or countless other matters (Kornfield 2005). I have been meditating for several years, but each time I seem to spend more time in automatic thoughts rather than witnessing my breath or bodily feelings.

The struggle to stay in the present, not allowing the ego to dominate, can make even a short time period of mediation seem lengthy. There is a humorous hint about this in the Julia Roberts film 'Eat, Pray, Love.' While meditating in a group, she looks up that overhead clock, which says 7:09. The voice-over continues her stream of thought about several issues. When she looks again, the time is still 7:09.

Another example of the domination of the everyday self is suggested by persons hearing music in their heads. At times it seems difficult to stop. There is also an extreme version of this kind of music - for some persons, their internal music is so uncontrollable that the afflicted person thinks it is coming from the outside, a hallucination. A well-known psychoanalyst, the late Leo Rangell, has described his own musical hallucinations and those of others (2009, with a forward by Oliver Sacks). In Rangell's case and some of the others, these hallucinations occurred virtually every day for much of their later life.

\section{The Ego or Everyday Self}

Why is the everyday self dominant, when it has so much less to offer than the hidden self? Although there are now many studies showing that mindfulness or access to the hidden self, is helpful, I haven't found any about the construction of dominance by the everyday self. Why is there an everyday self and why is it so dictatorial and simpleminded?

One possibility concerns the way that we learn and use language. In modern societies, we not only learn a language, but also learn to be extremely quick in using it. To understand the need to be judged com- 
petent in conversation, or at least not ridiculed, consider the complexity and ambiguity of ordinary human discourse. Human languages in actual usage are almost always fragmented, incomplete, and context dependent, with most commonly used words having more than one meaning. For these reasons, even simple discourse would be impossible to understand directly, taken literally. We understand the speech of others to the extent that we can take on, however briefly, their point of view. This role-taking gives rise to complex multiprocessing, as described below.

Most role-taking by adults appears to occur at lightning speed, so fast that it disappears from consciousness at an early age. In modern societies, particularly, those that strongly encourage individualism; there are many incentives for forgetting that one is role-taking. Each of us learns to consider ourselves a stand-alone individual, independent of what others think. Children learn role-taking so early and so well that they forget they are doing it. The more adept they become, the quicker the movement back and forth, learning through practice to reduce silences in conversation to an unbelievably short time.

Studies of recorded conversations of adults such as the one by Wilson and Zimmerman (1986) help us understand how forgetting the whole inner process is possible. Their study analyzed adult dialogues nine minutes long in seven conversations (with fourteen different people). In the segments recorded, the average length of silences varied from .04 to .09 seconds. How can one possibly respond to the other's person comment in less than a tenth of a second? Allowing a whole minute silence, rather than a tenth of a second, would make the pace of response six hundred times slower. Apparently one needs to begin forming a response well before the other person has stopped speaking, perhaps even during the first few seconds. That is, humans are capable of multiprocessing, in this case, in at least four different channels: listening to the other's comment, imagining it's meaning from the speaker's point of view, from their own point of view, and forming a response to it. These four activities must occur virtually simultaneously. There may be even further channels, such as imagining the other person's response to our forthcoming comment. These reactions give rise to very rapid back and forth between two or more channels: a vast interior drama could occur inside each person unknowingly in a dialogue, before each response.

\section{To THE LIGHTHOUSE}

This interior drama was foretold by the novelist Virginia Woolf. Lehrer (2008) has also pointed to Woolf as one of the literary 'neuroscientists' who foretold the nature of thought and of the self long before science. His chapter uses passages from two of her novels, Mrs. Dalloway and To the Lighthouse to show how she implied current scientific approaches to 
the emergence of the self. I will also use a passage in To the Lighthouse, but a different one than Lehrer. Also my explanation attempts to show how Woolf's treatment goes into exquisite detail about the structure of the self. One of the inner monologues by the protagonist, Mrs. Ramsey, is well known in world literary criticism. It occurs while she is measuring a stocking she is knitting on her grandson's ankle, between her comments to him only a few seconds long (I have divided the passage into three sections):

1. Never did anybody look so sad. Bitter and black, halfway down, in the darkness, in the shaft which ran from the sunlight to the depths, perhaps a tear formed; a tear fell; the waters swayed this way and that, received it, and were at rest. Never did anybody look so sad.

2. But was it nothing but looks? People said. What was there behind it - her beauty, her splendor? Had he blown his brains out, they asked, had he died the week before they were married - some other, earlier lover, of whom rumors reached one? Or was there nothing? Nothing but an incomparable beauty which she lived behind, and could do nothing to disturb? For easily though she might have said at some moment of intimacy when stories of great passion, of love foiled, of ambition thwarted came her way how she too had known or felt or been through it herself, she never spoke. She was silent always. She knew then - she knew without having learnt. Her simplicity fathomed what clever people falsified. Her singleness of mind made her drop plumb like a stone, alight exact as a bird, gave her, naturally, this swoop and fall of the spirit upon truth which delighted, eased, sustained - falsely perhaps.

3. "Nature has but little clay," said Mr. Bankes once, hearing her voice on the telephone, and much moved by it though she was only telling him a fact about a train, "like that of which she molded you." $\mathrm{He}$ saw her at the end of the line, Greek, blue-eyed, straight-nosed. How incongruous it seemed to be telephoning to a woman like that. The Graces assembling seemed to have joined hands in meadows of asphodel to compose that face. Yes, he would catch the 10:30 at Euston.

"But she's no more aware of her beauty than a child," said Mr. Bankes, replacing the receiver and crossing the room to see what progress the workmen were making with an hotel which they were building at the back of his house. And he thought of Mrs. Ramsay as he looked at that stir among the unfinished walls. For always, he thought, there was something incongruous to be worked into the harmony of her face. She clapped a deerstalker's hat on her head; she ran across the lawn in galoshes to snatch a child from mischief. So that if it was her beauty merely that one thought of, one must remember the quivering thing, the living thing (they were carrying bricks up a little plank as he watched them), 
and work it into the picture; of if one thought of her simply as a woman, one must endow her with some freak of idiosyncrasy; or suppose some latent desire to doff her royalty of form as if her beauty bored her and all that men say of beauty, and she wanted only to be like other people, insignificant. He did not know. He did not know. He must go back to work.

Given the circumstances, between her comments in a dialogue with her grandson, this monologue could have taken only 2 or 3 seconds at most. Since it requires 495 words to describe, the rate of thought would be about a thousand words a second. This rate, perhaps more than a hundred times the rate of speech, hints at the speed at which the brain is multiprocessing.

This monologue was first noticed by Auerbach (1953), who praised its psychological realism. However, he found section \#3, concerning William Bankes, somewhat puzzling. Although it begins with a comment Bankes made to Mrs. Ramsay in a telephone conversation, it expands to his own thoughts and actions, seeming to belong in his consciousness rather than in Mrs. Ramsay's.

In my view, the section gives further testimony to Woolf's uncanny psychological acumen, because it unmistakably foretells the idea of roletaking. This cadenza is a dialogue, or at least it begins with what seems to be an actual dialogue, a phone conversation between Mrs. Ramsey and William Bankes. But the phone conversation is taking place not from her point of view, but from Bankes. This difference of point of view may be heralded by the fact that Woolf has enclosed the whole section within parentheses.

The section starts with a compliment that Bankes pays to Mrs. Ramsay: "Nature has but little clay like that of which she molded you." But within this quotation a feeling of Bankes is noted, that he was moved by her voice. The section goes to comment on how he sees her as Greek, and so on, and his feeling that it was incongruous to be phoning her, that her face had been assembled by the Graces. Then, following the series of compliments, both external and internal, Bankes states, either to Mrs. Ramsay or to himself, that yes, he would catch the 10:30 train, which is what the phone call is ostensibly about.

The point of view is obviously not Mrs. Ramsay's, but Bankes'. How could this be? Woolf has shown that Mrs. Ramsay remembered and imagined a sequence of events beginning with an actual compliment to herself, but then going on to carry through the compliment to a sequence of thoughts and activities as they might have occurred to Bankes.

Mrs. Ramsay knew that Bankes was an admirer of hers, and she also knew his habits quite well. In the cadenza she shows some of her knowledge of him (for example, his habit of watching working men at 
a construction site when gathering his thoughts). She is thinking of the problem of Mrs. Ramsay and her beauty from the point of view of an admirer of hers.

She is imagining herself from Bankes' point of view, just as Woolf, in the monologues, is imagining the world from Mrs. Ramsay's point of view, a world within a world. Just as Mrs. Ramsay was able to plausibly construct the world from Bankes' point of view, because she knew him well, so Virginia Woolf was able to plausibly construct the world from Mrs. Ramsay's point of view, since she knew so well the model (her own mother, Julia Stephen) on whom Mrs. Ramsay was based.

In this instance, Woolf has described in detail not only the spectacular speed of interior monologues, but also a way in which it involves role-taking. Quoting Cooley once again, "We live in the minds of others without knowing it." By implication, Woolf's recognition of role- taking, her own invention, and the lengthy and slapdash structure of the monologue also has a third implication, that Woolf used her own witnessing self to write this novel, and was aware that she was using it.

\section{Modern and Traditional Societies}

In modern societies, at least, if one is to respond quickly enough in dialogues, one must split one's attention into at least four parts. I assume that the length of silences is greater for small children who must learn this drill. Learning to respond quickly probably takes years. Perhaps early in grammar school, most children have obtained sufficient speed. If a child takes too long to respond, undesirable interpretations may be put upon the pause. "What are you, stupid or something?" Are you listening to me?" "Don't you believe me?" or other complaints.

Multiprocessing for speedy response seems to have two important drawbacks. First, it focuses attention on the words, the simplest or at least the most obvious parts of a message. This focus tends to reduce attention to the paralanguage and gestural components of speech, or ignore them entirely. Since the non-verbal components carry most of the social-emotional message of speech, speed responses weaken relationships, already weak in the alienation of modern societies.

A second drawback involves a tendency toward repetitiveness, developing a kind of automation of response that also weakens understanding and therefore the relationship of the speakers. There are several studies of traditional societies that suggest that their speed of discourse might be intentionally slow. Here I will discuss one of them, the study of ab- 
origines in Australia by Liberman ${ }^{1}$ (1985). Although he did not measure the structure of silences directly, it is clear from his comments and the examples of dialogue in groups that the pace is much, much slower than in modern societies, and much more oriented toward mutual understanding than individual expression (1985, 19 ad passim).

One striking indication of the slowness of pace and orientation toward mutual understanding is the practice of responding to a comment by merely repeating it, which occurs quite frequently. Another is what Liberman names 'calls for consensus,' which occur frequently in group discourse. These practices are clear indications that social relationships are far more important than speed, and also individual expression. These practices weaken individual identity, but they secure the bond with others. There must be much less demand for speed of response as children learn their native tongue.

Another more subtle indication is that in the aboriginal language, the word for listening also means thinking $(1985,15)$. This double meaning suggests that even individual thinking in this group is social - one thinks by listening to others. Indeed, this usage comes close to Cooley's thesis, that we live in the minds of others. Unlike the denizens of modern societies, these traditional people seem to know it. Perhaps the relatively slow pace of discourse is one of the reasons for the seeming effectiveness of shamans, medicine men and women, even in small tribes. Because of the slower pace, their everyday self might be less automated and less dominant over their hidden self than in modern societies, enabling them to be better healers.

\section{Self ANd Ego}

Acquiring a human self depends on role-taking; the ability to see one's self as another might, as well as from the inside. The problem is that in order to be quickly responsive, a part of the self, the everyday self or ego, may come to rely on repetitive or stock responses. How can one listen to a comment, imagine the others' point of view, decide one's own point of view, and produce a response, but leaving a silence of less than a tenth of a second? It seems that such a facility would require a mechanism that is virtually automatic, using, for the most part, stock responses, rather than an exact response that would precisely fit the particular moment.

Automatized responses in conversation could involve the use of hundreds of stock words, phrases, or sentences, rather than exploring the limits of human responsiveness. The hidden self is capable of providing

1. Thanks to Geoffrey Raymond for this reference. 
a unique response to each unique situation. But such a response requires that one listen carefully with one's full attention directed at the speaker, leading to delay in response. Instead, the ego becomes like a machine, composed largely of ready-made elements. Ego responses, therefore, are as much or more about the self as about the other or the situation. Punning, for example, is a stock resource that has little if anything to do with the present situation, being entirely and only about the words being used.

An obvious example of a stock response would be "Well!" or "Uhh," to gain time. But since there is next to no time for the further response either, what usually occurs is also stock, perhaps a saying, or a favorite phrase, or phrases that one knows is one of the other's person favorites, or some more complex response that is still mostly constructed from the available stock. Many couples frequently resort to phrases from pop songs and punch lines from jokes: "Don't think twice"; "Can I see that map again?" and so on.

However, many responses are somewhat more complex. They could involve some on-the-spot construction, but still are partially tangential. Most of us have 'lines' we take with particular people and situations that persist, regardless of changes in the other person or situation. My father, for example, took an authoritarian line with my mother, brother and me, and we took a submissive line with him, even after my brother and I were out of his direct influence. Knowing what to expect from the other person, and from ourselves, even approximately, would be considerable help in keeping silences short.

\section{Dreams}

The ego can be envisioned as that part of the self that is often automated. The internal dialogue of the self is between the automated part and the part that can respond to situations de novo, the hidden self. It appears that the ego is in charge almost all of the time. Most dreams would be an obvious example. Dreams appear to be produced by a fully automated ego, since the dreamer has no control over their content. Lucid dreams, where the dreamer is aware that he or she is dreaming, are an important exception, since the deep or witnessing self is watching the productions of the ego. Perhaps we should also consider dreams that are the opposite of lucid - one thrashes about or feels painful emotions because the dream is taken to be really happening.

The difficulty that many people have with learning to meditate seems to be caused by the domination of the ego. Meditation involves restraining the ego, moving toward being able to observe own ego, as well as ex- 
periencing it. The idea of the self being not only an actor, but also having the ability to be a witness to one's actions, turns out to be exceptionally important in many ways. As writers like Lawrence have suggested, creative ideas can pour out of the witnessing self effortlessly. As discussed above, witnessing self is the crucial part of role-taking of living in the minds of others. But there is also another product of witnessing self that has been much less noticed - the role it plays in the management of emotions.

\section{A SAfe Zone for Intense Emotions}

The earliest version of the idea for emotions is found in Aristotle's theory of the theatre, that the purpose of drama is to help audiences resolve their unresolved emotions. The trick, according to modern drama theory, is for members of the audience to actually feel the emotions the actors arouse, but at the same time stay aware that they are only watching a play. The key idea is called distancing - the emotions aroused are not painful because they are not too close (under-distanced) and not too far (overdistanced.) Over-distancing involves too little emotion; in the theatre, the audience would be unmoved by the play. Underdistancing means too much; the audience relives painful experiences rather than resolving them. Overdistanced therapy is talky — the client remains firmly in his or her head. At optimal distance, the attention and encouragement by the therapist allows the client to relive unresolved emotion, but also to watch him or herself doing it.

Levine (2010) has described optimal distance in different terms as a process he calls 'pendulation.' One swings back and forth between experiencing the emotion and watching one's self experiencing it. This process leads to a feeling of comfort even in the presence of intense emotions. One feels in control and therefore safety, if there is too much pain, one can swing out. The notion of pendulation implies role-taking of a special kind - one is not only observing one's self from an outside point of view, but doing it rapidly enough so that one can relive hidden emotions, but this time with little or no pain.

\section{Conclusion}

In the framework outlined here, the actions of the ego resemble a dream state, since they may be created as much or more out of one's past as from the actual situation. The deep self, on the other hand, reacts to the exact situation at hand. Meditation might be a way to begin the long process 
of bringing this self out of hiding. Otherwise, each of us becomes more deeply alienated from others and self, and the more the usual speedy but superficial conversations take place.

As suggested by the instances of musical hallucinations, ego repetitions can become completely automatic, to the point that the person thinks they are outside the self. More familiarity with the structure/process of the ego and hidden self might provide a way of understanding symptoms of what is called mental illness. One possibility is that runaway automaticity of the ego is a way of hiding painful emotions (Scheff 2011).

Rangell (2009) and other psychoanalysts have described self process in terms of 'the executive function of the ego' and 'the autonomy of the ego.' Perhaps stronger language is needed, such as 'robotic' thought of the ego. We might use the term 'egoisms' instead of the term symptoms. At any rate, using the language of conflict within the self (calling hallucinations and other 'symptoms' runaway ego) might be much more appropriate that the language of health and illness. For one thing it could help move most cases out of psychiatry and medicine into psychotherapy and family/community help, where they usually belong. (For a brilliant illustration of the latter, see the film Lars and the Real Girl.)

Perhaps some ways of slowing down the pace of conversation can be taught to our children? How can we change our family and/or educational systems so that we could gain some access to the hidden self like Marilyn Nadler? Otherwise as individuals and as members of modern societies, we dream on.

In another section of Lawrence's poem, he continues:

Oh when man has escaped from the barbed-wire entanglement

of his own ideas and his own mechanical devices

there is a marvelous rich world of contact and sheer fluid beauty

and fearless face-to-face awareness of now-naked life

and me, and you, and other men and women...

\section{REFERENCES}

Auerbach, Erich. 1953. Mimesis: The Representation of Reality in Western Literature. Princeton, NJ: Princeton University Press.

Bargh, John and Tanya Chartrand. 1999. The Unbearable Automaticity of Being. American Psychologist. 54: 7, 463-479

Brown, K. Ryan, R. Creswell, D. 2007. Mindfulness: Theoretical Foundations and Evidence for its Salutary Effects. Psychological Inquiry. 18: 4, $211-$ 237 
Cooley, Charles. 1922. Human Nature and the Social Order. New York: Charles Scribner's Sons

Gladwell, Malcolm. 2005. Blink. New York: Little, Brown.

Kornfield, Jack. 2005. Meditation for Beginners. Berkeley: Sounds Good.

Lawrence, D. H. 1932. Terra Incognita. Complete Poems. London: Penguin.

Lehrer, Jonah. 2008. Proust was a Neuroscientist. Boston: Houghton Mifflin

Levine, P. A. 2010. In an Unspoken Voice. Berkeley: North Atlantic Books.

Liberman, Kenneth. 1985. Understanding Interaction in Central Australia. Boston: Routledge.

Mead, George. H. 1934. Mind, Self, and Society. Chicago: U. of Chicago Press.

Miller, Dale, Benoit Monin, and Deborah Prentice. 2000. Pluralistic Ignorance. in Attitudes, Behavior, and Social Context, edited by Deborah Terry and Michael Hogg. Mahwah, NJ: Lawrence Erlbaum.

Marks, G., and N. Miller. 1987. Ten Years of Research on the False-Consensus Effect: An Empirical and Theoretical Review. Psychological Bulletin 102(1), 72-90.

Moors, Agnes and Jan De Houwer. 2006. Automaticity: A Theoretical and Conceptual Analysis. Psychological Bulletin. 132, 2, 297-326.

Ouspensky, P. D. 1949. In Search of the Miraculous. New York: Harcourt Brace.

Pascal, Gabriel. 1660. Pensees. (Thoughts). Paris: Editions du Cerf. (1982)

Rangell, Leo. 2009. Music in the Head. London: Karnac.

Rosenblatt, Paul. 2009. Shared Obliviousness in Family Systems. Albany: State University of NewYork.

Scheff, Thomas. 2011. Social-Emotional World: Mapping a Continent. Current Sociology 59: 3, 347-61.

Wilson, Thomas and Don Zimmerman, 1986. The Structure of Silence between Turns in Two-party Conversation. Discourse Processes 9:4 (OctoberDecember): 375-390.

Woolf, Virginia. 1927. To the Lighthouse. New York: Harcourt (1989).

Thomas Scheff is Professor Emeritus, UCSB, and the author of many books and articles. His principle interests are emotions, causes of destructive conflict, and more integration of disciplines. He believes that the current division into separate fiefdoms is a disaster. One book, Emotions, the Social Bond., is an approach to integrating the social sciences, particularly sociology and psychology, and ending separation from the humanities. As in the physical sciences, advances and practical application both depend increasingly on integration between disciplines. His most recent book concerns the emotions hidden in pop song lyrics: What's Love Got to Do With It? 
330 C Canadian Journal of Sociology/Cahiers Canadiens de sociologie 39(3) 2014 